Supplement of Biogeosciences, 18, 2275-2287, 2021 https://doi.org/10.5194/bg-18-2275-2021-supplement (c) Author(s) 2021. CC BY 4.0 License.

(c) (1)

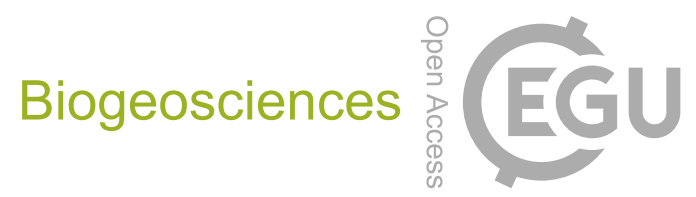

Supplement of

\title{
Divergent climate feedbacks on winter wheat growing and dormancy periods as affected by sowing date in the North China Plain
}

Fengshan Liu et al.

Correspondence to: Fengshan Liu (liufs.11b@igsnrr.ac.cn)

The copyright of individual parts of the supplement might differ from the article licence. 


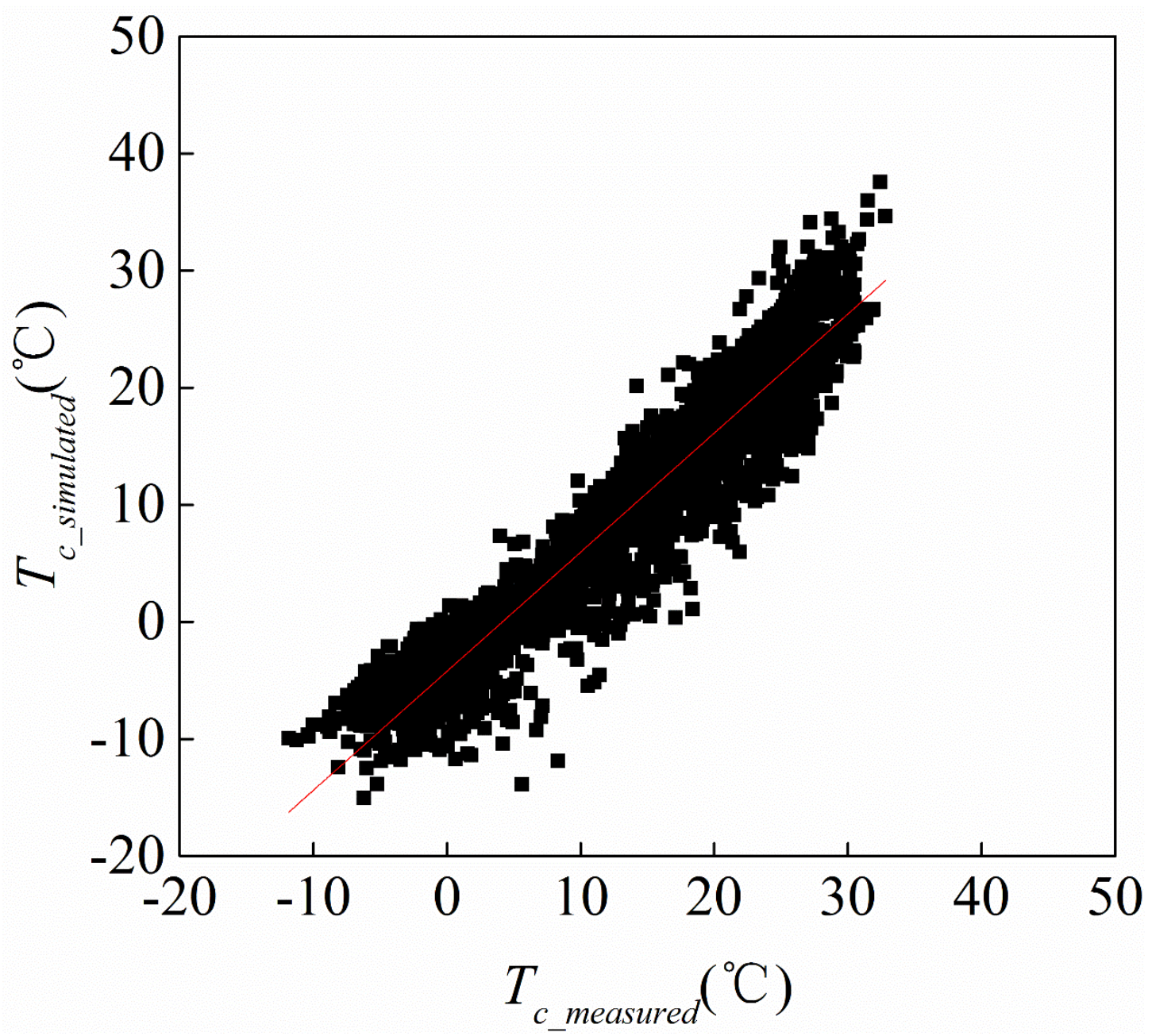

Fig.S1 The relationship between simulated canopy temperature $\left(\mathrm{T}_{c_{-} \text {simulated }}\right)$ and measured canopy temperature $\left(\mathrm{T}_{c_{\_} \text {measured }}\right)$ at Yucheng station over 2003-2010 Linear regression equation: $\mathrm{T}_{c_{-} \text {simulated }}=1.02 * \mathrm{~T}_{c_{-} \text {measured }}-4.22, \mathrm{R}^{2}=0.91, \mathrm{p}<0.001$

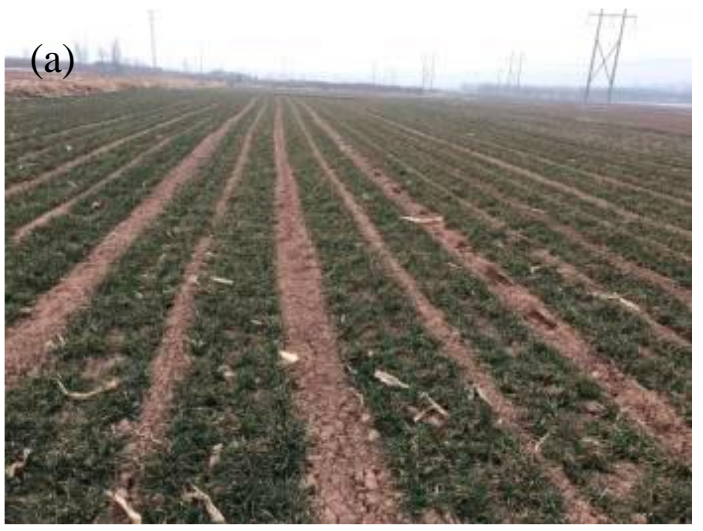

(b)

Fig.S2 Land surface characteristics of winter wheat in re-greening period for (a) early and (b) late sowing date. Photos taken by Liu Fengshan in Fengjiafangzi Village, 
Jinzhongzi Town, Anqiu City, Shandong Province, on February 25, 2018.

Table S1 The coverage differences between two scenarios of snow and crop in the 4 phases at selected 10 stations

\begin{tabular}{|c|c|c|c|c|c|c|c|c|}
\hline \multirow{2}{*}{ Stations } & \multicolumn{4}{|c|}{ Snow coverage } & \multicolumn{4}{|c|}{ Crop coverage } \\
\hline & Phase 1 & Phase 2 & Phase 3 & Phase 4 & Phase 1 & Phase 2 & Phase 3 & Phase 4 \\
\hline Miyun & 0 & 0 & 0 & 0 & 0.927 & 0.009 & 0 & 0 \\
\hline Baodi & 0 & 0 & 0.01 & 0 & 0.919 & 0.011 & 0 & 0 \\
\hline Tangshan & 0 & 0 & 0 & 0 & 0.917 & 0.013 & 0 & 0 \\
\hline Huanghua & 0 & 0 & 0 & 0 & 0.827 & 0.002 & 0 & -0.001 \\
\hline Weifang & 0 & 0 & 0 & 0 & 0.82 & 0 & 0 & 0 \\
\hline Xinxiang & 0 & 0 & 0.01 & 0 & 0.768 & 0 & 0 & 0.001 \\
\hline Zhengzhou & 0 & 0 & 0 & 0 & 0.764 & 0 & 0 & 0.002 \\
\hline Shangqiu & 0 & 0 & 0.01 & 0.01 & 0.753 & 0 & 0 & 0.001 \\
\hline Nanyang & 0 & 0 & 0.01 & 0 & 0.719 & 0 & 0 & 0.003 \\
\hline Zhumadian & 0 & 0 & 0.01 & 0 & 0.741 & 0 & 0 & 0.003 \\
\hline
\end{tabular}

